\title{
Theoretical Foundations of Translation Studies
}

\author{
Mehran Zendehboudi ${ }^{1} \&$ Mohammad Reza Farsian ${ }^{1}$ \\ ${ }^{1}$ Ferdowsi University of Mashhad, Iran \\ Correspondence: Mehran Zendehboudi, Ferdowsi University of Mashhad, Iran. E-mail: mehranzen@um.ac.ir
}

Received: May 30,2016 Accepted: August 8,2016 Online Published: December 1, 2016
doi:10.5539/ijel.v6n7p144 $\quad$ URL: http://dx.doi.org/10.5539/ijel.v6n7p144

\begin{abstract}
Epistemologies of translation are a complicated subject that is beyond the scope of this article. As such, only the critical points have been addressed in this paper. One key epistemological issue is the analysis of discourse in any science. In this article, four scenarios of translation studies have been discussed. An underlying concept in translation studies is the issue of fidelity in translation. In this paper, the trajectory of this concept is analyzed in brief. It is followed by a reflection on two fundamental concepts of source oriented (Sources) and target oriented translation approaches, as they occupy a particular position in the translation. The last section of the article investigates dichotomies in the field of translation studies, including the theory of the action, the untranslatability versus translatability, art versus science, and etc. In this paper, we try to study theoretical principles of translatology. So we consider four important speeches of Jean Rene Ladmiral: Prescriptive translatology, Descriptive translatology, Productive translatology, scientific translatology and then we consider faithfulness in translation. Ladmiral suggests two concepts for fidelity in translation: The source oriented (sources) and target oriented. These two concepts are the fundamental concepts in translatology. In the next step the translation science is investigated in various languages such as English, German and at last in French. Finally, we take a look at binary concepts: Theory vs. action, Translatability vs. untranslatability, Art vs. Science. This paper is in epistemology scope of translation and does not have pedagogical aspect, in other words, it is a function-oriented translation.
\end{abstract}

Keywords: fidelity in translation, Jean-René Ladmiral, source oriented, target oriented

\section{Introduction}

According to Jean-René Ladmiral the founder of the French translatology, the epistemology of human sciences is not merely a branch of philosophy. He posits that epistemology in human sciences is inherent in each of its branches. So, it is impossible to study linguistics, sociology, psychology, etc, without pondering upon its position and challenging its diverse concepts. Translatology also falls within the realm of human sciences, and it requires an epistemology of its own (Ladmiral, 1987). In this paper, key discourses in the field of translation are discussed and followed by an analysis of underlying concepts in translation.

Describing linguistic behaviors are essential for understanding the universe in every scientific study of its theoretical foundations and constituent elements that science needs to be considered. Another important point is its explanation of the founders (Ladmiral). The oldest problem in the translation is loans issues, which none of the translation theories can pass this concept. Translation studies should also examine the theoretical basis for understanding the concepts in the science.

In the Epistemologies field of translation, researches have been scattered, but some separate studies in the form of an article were written by Ladmiral.

This paper is a theoretical study which puts Epistemology approach in new viewpoint and analyzes Ladmiral's discourse translatology and has a new look to the binary concept. Our supposition is not based on the historical discourse of translatology.

Classification starts from four discourses of translatology and then considers faithfulness of translation and its sub-classifications and ends to binary concepts. The logical trend of this classification is the most important aim of this paper. 


\section{Material Studied}

\subsection{Four Categories of Speech}

As mentioned earlier, the epistemology of translatology should take into account the range of discourses prevailing in this field. Jean-René Ladmiral divided these discourses into four classes.

Ladmiral's discourse translatology figures all aspects of translatology briefly although he does not claim a particular theory. He just helps to have a better understanding of translation phenomenon.

\subsubsection{Prescriptive Translatology}

Similar to the traditional grammar, this discourse tends to be prescriptive in nature, thus standing in sheer contrast with the descriptive linguistics. He put seminal theoretical works with philosophical or literary approaches to translation, such as the works of Walter Benjamin, Henri Meschonnic, Valery Larbaud, Jose Ortega Y Gasset or George Steiner in this category. In addition to these major works, Ladmiral added conventional translation textbooks to this category. Then translatology provided a translator with rules and laws of translation, which "prescribe" him/her how to translate. Ladmiral said, "To put it briefly, it should be stated that these works belong to the pre-linguistic thinking on language and translation, which are often ideologically or philosophically loaded. In fact, a significant share of published works falls into this category. I call it translatology of yesterday" (Ladmiral, 1987).

\subsubsection{Descriptive Translatology}

The second type of translatology discourse is concerned with the most common types of discourse, which has been at the center since post-World War II. In his comparison of prescriptive grammar and descriptive linguistics, Ladmiral defined this discourse as descriptive translatology. It was entwined with linguistics with its works adopting an adaptive approach. Some notable theorists of this discourse are Jean-Paul Vinay, Jean Darbelnet, Jacqueline Guillemin Fletcher, Michel Ballard and Georges Mountain. The reason that Ladmiral lumped all of this figures together, is that they have a clear orientation which is a posteriori in nature. He called it translatology of yesterday, which is especially useful for translation teachers (Ladmiral, 1998).

Such a discourse which explores comparative linguistic analyses surrounding the source and target texts has the merit of supplementing the linguistic competence of students; something that cannot be easily overlooked by the education institution (Ladmiral, 1998).

In schools of translation teaching, such as "ESIT" (School of Conference Interpreting and Text Translation) in Paris, the assumption is that students entering this school should possess excellent language competency bereft of any need for further language training. However Ladmiral, posited that through the descriptive translatology discourse, supplementary language training can also be provided as a part of the translator training courses (Ladmiral, 1998).

\subsubsection{Productive Translatology}

The third discourse of Ladmiral allegiance is productive translatology. Before scientific study of translation, the day-to-day necessity of translations compelled this French translation scholar to propound productive translatology. A notable instance of this discourse is his "Théorèmes pour la traduction". Like Descartes, who had self-imposed interim rules, Ladmiral also raised theorems of translation. Descartes says, "In an attempt to eschew any hesitation in my works, albeit reason forces me into his adherence, I have self-imposed interim rules" (Ladmiral, 1987).

From the perspective of Ladmiral, translation is a mental action consisting of two stages: "In fact, going from the source text (ST) to target text (TT) does not happen in a linear and direct way but through two stages, reading and interpretation and re-creation". Ladmiral, however, assumes that there is an in-between phase called "deverbalization". It is from here that the message proceeds from the verbal linguistic stage of the source language (SL) to the cognition stage, during which the translator must forget SL signifiers in an attempt to grasp the signified or the meaning of the message. So it can be represented in the form of the target language (TL). The purpose of this theoretical discourse is not to present a systematic theory of translation (Ladmiral, 1987).

He sleeked to provide a set of concepts and principles to anticipate problems facing translators and facilitate their resolution. This discourse is closely related to the psychology of translation, but the question is the type of psychology. The intended psychology is more general in nature and closer to meaning to the personality psychology or psychoanalysis (Ladmiral, 1987).

What expected of this translatology is that it provides us with a conceptual vehicle for contemplation on our work. Productive translatology is the study of conceptualizing contrasts surrounding the translation action. The 
internal psychology of productive psychology strives to aid a translator through verbalization to figure out the range of problems with a specific tag (Ladmiral, 1987).

This realm of translatology resembles Freud's thoughts in which the patient verbalizes his issues as a way of overcoming them. The primary merit associated with the verbalization of translation is the ability to name translation problems as we face them, especially the solutions discovered for each so that we can reconstruct the pleasure of translation as it is being typed with our keyboard (Ladmiral, 1987).

Semantic separation has two critical functions: first, is labeling experiences and the second is distancing ourselves from translation problems and getting closer to solutions. Ladmiral calls this discourse "translatology of today."

\subsubsection{Scientific Translatology}

"Translatology of tomorrow" embodies the fourth type of translation discourse recognized by Ladmiral, which is primarily aimed at analyzing the brain function of translators during the translation process. Ladmiral refers to it as the translatology of tomorrow for it takes a long time for the researcher to study the subject under investigation (Ladmiral, 2002).

It is more convenient to study the work of a conference interpreter compared to a text translator as it allows recording video or audio files related to the act of interpreting. A host of studies has been undertaken by brain imaging. This type of translatology has no impact on the translation action or translator training. Ladmiral warns of the risk of expecting it to work a miracle (Ladmiral, 2002).

\subsection{Faithfulness in Translation}

The first discussion of a faithful translation was presented in the translation of Septante interpreted by Jewish Philo. For him, this translation was faithful to the word for word translation was seen to be more fitting to the sacred text. More than two thousand years ago, Cicero argued against word by word (Verbum proverb) translation for sense for sense translation. "The idea remains the same. I did not see the necessity translate word for word" (Zendehboudi, 2007).

In the case of St. Jerome, he has explicitly articulated his translation principle that prioritizes sense over the word. It is the whole meaning that ought to be translated not the words alone. St. Jerome disallowed word by word translation except for the translation of scriptures. For this reason, he considers two types of translation: translation of meaning (sense-for-sense) and translations of scriptures (word for word) (Zendehboudi, 2007).

After the fall of the Roman Empire in the Middle Ages, translators continued to propound theoretical principles. Boyce, who translated from Greek to Latin, asserted that word for word translation is required to retain the heart of truth. He also says, "A good translation does not take pride in its beauty but rather in the simplicity of its content and detailed characterization of words" (Zendehboudi, 2007).

It was during this period that the literal translation grew in popularity, especially thanks to Boyce. However, certain doubts were cast about the term literal translation. For instance, Anastasia wrote a letter to Pope John VIII wherein he had posited that literal translation did harm to TL and disturbed the readers (Zendehboudi, 2007).

Also, Christian religionists believed that bad translations of scriptures sprang from the word for word translation. For this reason, St. Thomas considers wrong translations as the gateway to the darkness.

In the fourteenth century, Leonardo Bruni rejected word for word translation by postulating that the observance of grammar rules did not necessarily result in the transfer of meaning. In the sixteenth century, Etienne Dolet proposed his set of principles of translation, according to which a translator needed to make perfect sense of the subject under translation without which a faithful translation was far-fetching (Zendehboudi, 2007).

He believed that a translation was only useful for conveying the meaning, which made it inferior to the ST. He rejected reliance on style, especially for the translation of poetry. For him, poetry was untranslatable, unless the translator had a poetic sense resembling that of the original poet. In this century, the great Jacques Amyot introduced the concept of adaptation in translation. In fact, in his translations of ancient works, Amyot had adapted those works to the taste of his contemporaries. He said, "It is not sufficient to translate the author; a spark of creativity should also be applied to translation" (Zendehboudi, 2007). In the Classic Age (from late 16th century to the early 18th century), the golden age of translating ancient Greek and Latin poetry commended. Across the Europe, poets endeavored in translation. The free translation, also known as Infidel beautiful (Les belle's infidèles) was also common during that time. Nicholas Perrot d'Ablancourt and his followers stimulated the enduring fascination. 
With the establishment of French Academy in 1640, translators struggled to enrich the French language with the beauty of the ancient works. They believed that the principles proposed by Cicero and St. Jerome (to give the reader not the same number of words but the same weight) justified any deletion and addition in translation. In the twentieth century, Gorges Mountain in his book Les belle's infidèles presented a series of theoretical arguments for the rejection of word for word translation (Mounin, 1955). He introduced two methods of translation.

-Tainted glasses: These are a word for word translations. By reading TT, one can see the footprint of the SL, time differences, cultural disparities and so forth. It is as though one is looking at the world through a tainted glass.

-Transparent glasses: There are translations not tainted with the color of translation as if the text is written directly to the target language. The translator is faithful to the text and the TL (Mounin, 1955).

Jose Ortega Y Gasset takes into account both types of translations, suggesting that the language of the authors should be put into perspective (literal translation should be practiced) (Zendehboudi, 2007).

According to Walter Benjamin, a translation is not the copy of an original text. For him, a true translation does not conceal the original wording, and the trails of ST are evident in it. Jean-Claude Margot posits that a faithful translation recreates in his readers the same effect the ST had on his reader (Zendehboudi, 2007).

The school of conference interpreting and text translation, proposing the interpretive theory of translation or the theory of meaning, argues that translation is always feasible, in as much as it is not concentrated on language but the content of message or text (Zendehboudi, 2007).

The proponents of this theory recommend translators not to translate, but to express the sense they grasp. For appropriate perception, one should reflect upon the quality of things said by the speaker, the readers and the situation in which words are exchanged (Zendehboudi, 2007).

\subsubsection{The Source Oriented (Sources) and Target Oriented (Cyclists)}

Ladmiral in his speech at a conference on translation held from 16 to 19 June 1983 in London introduced these new terms for the first time in the French language. The two terms have gained their position in the dictionary of translatology terms in French. Developing these terms in an article (Ladmiral, 1986), He turned them into two key concepts. These terms are widely used in translatology discourses. However, one may ask why these two words, which seek to take the place of some existing terms, have enjoyed such wide acceptance. That is, if they were merely two words replacing existing terms, they would never rose to such a place in the discourses of cognitive translatology. The justification for the presentation of these conditions has been described by their creator as: "That I risked coining these terms is because they built images that allowed the examination of the faithfulness issue in translation from a more accurate perspective" (Ladmiral, 1986).

The source oriented and target oriented proposed by Ladmiral resemble the formal equivalences (équivalence formula) and dynamic equivalences (équivalence dynamic) of Nida. It can be argued that the source oriented in the discourse of Ladmiral correspond to the stained glass of Men and formal equivalence of Nida whereas the target oriented are reminiscent of a transparent glass of Men and dynamic equivalence of Nida (Ladmiral, 1986).

The source oriented translators like Antoine Berman and Henri Meschonnic have a tendency to treat ST as a sacred text. Rather than relying on text, they put their faith in the language of the source text which is surrounded by a halo of sanctity. On the contrary, the target-oriented translators take advantage of the richness of target language while allowing a more distinctive role to the translator in this process (Ladmiral, 1986).

\subsection{Science of Translation}

Ladmiral refers to designations that reflect the science of translation in English, German and French languages, with each having a distinctive connotation. "In English, the term Translation Studies indicates the Anglo-Saxon empirical epistemology and thus provides a broad definition of the scope of this discipline. In German, Übersetzung wissenschaft can be roughly translated as the science of translation, which evokes a positivist meaning" (Ladmiral, 1998).

Now let us explore the exact meaning of science of translation in German. In a way, the meaning should be explained. To answer these questions, this author, who is also the translator of German philosophy, is willing to go into his experience of translation. Wissenschaft in German is much broader than science in French. In French, it refers to coherent and organized knowledge that responds to the requirements of logics and mathematical science. In the German, any science with a specific methodology which can be placed in university courses is called Wissenschaft. Finally, for philosophers like Heidegger, theology is also a form of Wissenschaft (Ladmiral, 
1971).

The concept of the translation in French takes into account both sides of the coin. One the one hand, it refers to a set of studies, information, thoughts on the translation and the other hand it involves a determination to establish an academic discipline, almost a science. In a general interpretation of Ladmiral's perspective, all phenomena and studies are about translation. In a specific sense, the theory of translation or some theoretical concepts constituted the heart of translatology.

According to Ladmiral, the aim of translatology is to generate a linguistic theory of translation (Zendehboudi, 2007).

Henry Meschonnic, however, adopts a different view. What is interesting is that despite being a critical translation theorist, he refuses to recognize the science of translation and speak of the literary theory of translation (Zendehboudi, 2007).

During the last thirty years, there has been a host of theoretical studies about translations, which has contributed to the pessimism of translators. According to Guidère, for the acceptability of theoretical translation studies, some principles should be followed:

a) Cohesion principle: There should not be any internal conflict among studies.

b) Inclusion principle: studies must include the largest number of translation actions and offer the maximum number of possible samples.

c) Simplicity principle: Studies should have the minimum rules and concepts.

d) Predictability principle: It should allow predicting the reliability and accuracy of the new translations or novel solution (Guidère, 2011).

\section{Methodology}

Based on the concept of translation to the desired method of research, the history of translation studies is replete with binary concepts. In the following section, some three dichotomies inspired have been described (Guidère, 2011).

\subsection{Theory versus Action}

The contrast between theory and practice has been in place throughout the history of translation, putting translation teachers and translation practitioners against each other. Understanding this disparity is essential to figure out many of the issues raised in translation studies. This contrast incorporates some other concepts such as abstract-objective, fundamental practical and practical-impractical. Some translators deny the merits of any theory of translation. On the other hand, there are theorists who have never engaged in translation practice. As a result of this situation, neither can benefit from the achievements nor capitalize on the work experiences of the other.

Despite the large number of books written on translations in all languages, the share of translation practice is greater than that of theory. More than theorizing, translation practitioners have been engaged in translation action, which is per se indicative of the distance between theory and action. Van Hoof in his book on the history of translation in the West stresses the disparity between theory and action, saying that most translation theories only address translation practice partially, and translation history is of special importance in delineating the breadth of translation theories.

\subsection{Translatability versus Untranslatability}

The issue of translatability was first raised concerning the translation of sacred texts. Conflicting reactions to the translation of Old Testament relied on two points. For some scholars, translations allowed the propagation and spread of the word of God. The translation was a means to help humans understand the meaning of the scriptures. For others, the translation was a blasphemous act that cast doubt on the nature of Lord's words. Nida points out the critical position of scriptures in the history of interpretation, positing that, "No other type of translation does have such a prolonged history, and none has covered so wide a range of language" (Guidère, 2011). The Bible has been translated into more than 2233 languages (Oustinoff, 2003). Therefore, understanding the expansion of translation irrespective of the important influence of Holy Scriptures on translators over hundreds of years is difficult.

Apart from the fact that the translation of the Bible has been an effective vehicle for propagating the cause of Christians, this book has heavily impacted the translation action.

Van Hoof writes: "It should be stressed that the history of religions in general and the history of Western 
Christianity in particular, constitutes a rich and valuable resource for translation. The demands of burgeoning Christian community soon extended the issue of translating scriptures to other Latin languages as well (Van Hoof, 1991). This issue lies at the heart of translatability and untranslatability debate. In these binary concepts, it is possible to defend both sides of the argument. The question, "Is translation impossible or anything is translatable?" leads us to another binary concept: "Should we stay close to the source text or target text?" "Literal translation or communicative translation?" "Fidelity or beauty?" These concepts all address the same subject and are not contradictory. Those involved in the practice of translation are well aware that the translator retains both in perspective in the process of translation. It is something that appears to be paradoxical on the surface. That is, a translator not only attempts to be faithful in his rendering of the ST but also seeks to recreate and convey the aesthetic aspects of text as much as possible. It is worth mentioning that a translator does not render the source language but the text (in the written translation) or the speech (in conference interpreting)" (Zendehboudi, 2011).

\subsection{Prejudice Objection}

According to Jean-René Ladmiral, prejudice complaint represents "the impossibility of translation theory" (Ladmiral, 2002). Drawing on the ideas of Du Belly, Georges Mounin posits three arguments for rejecting theories of translation:

A. Dialectic argument (argument dialectic): Du Bellay rails against bad translations on the account that they harm the French language by importing unfamiliar words and structures. There is no denying that there are imperfect translations. No translation is perfect [...]. Since ancient times, there has been a myriad of bad translations, and they are equally prevalent today, and perhaps this tradition continue to persist in the future, and many bad translations will find their way to the book market. On the contrary, bad translations are proof of translatability. In fact, the existence of bad translations proves that there are good translations, thereby confirming the possibility of translation (Zendehboudi, 2002).

B. Historical argument: The second argument quoted by Mounin does not deal with translatability directly, but, like the first argument, puts emphasis on the deleterious effect of translation.

Ten years after the order of Carteret that announced French as the official language of France, Bu Bellay defended this language. He argues that this language is capable of expressing literary and philosophical ideas, and French writers are no longer under obligation to compose their scientific, literary and philosophical works in Greek. He posted that translation interrupted the consolidation of French. Montesquieu says, "If you keep translating ceaselessly, then no one would translate your works" (Zendehboudi, 2002).

C. Theoretical argument: According to Du Bellay, some original features of author's style and poetic characteristics rooted in the culture of different nations are untranslatable. Thus, we see that the initial question regarding the possibility of translation may lead to the question "Is poetry untranslatable?" (Zendehboudi, 2002).

\subsection{Art versus Science}

Guidère (2011) raised the issue of art versus science in the field of translation studies. One of the questions that have preoccupied many translators is whether the translation should be treated as an art or science. This question should be approached with caution, for the scientific characteristics of the translation are distinctive from that of science as commonly applied to empirical sciences like physics.

Vinay \& Darbelnet in the Comparative stylistics of French and English (Vinay \& Darbelnet, 1958) assert that they wish to distance themselves from theoretical approaches and turn to scientific approaches. In an attempt to bring these two approaches together, however, they argue that translation is an art if you have learned the techniques (Vinay \& Darbelnet, 1958). In this context, they propose seven criteria that are intended to stay as close as possible to scientific criteria. As pointed by Guidère, Vinay, \& Darbelnet propose a set of terms before their analysis to demonstrate the seriousness of their criteria.

According to Vinay \& Darbelnet, technical, scientific words sit at the borderline of artistic and scientific events. For them, translation is more than anything the practical application of comparative stylistics for linguists. Mounin (1976) also says, "One can say that translation is an art, like medicine, but founded upon scientific assumptions."

\subsection{Author versus Translator}

Today, there are two key figures in translation, namely the author and translator, although the division of roles has not been clear-cut because there are always some translating writers and some authoring translator. The contrast between these two has grown in intensity over the centuries (Guidère, 2011). Cary describes the 
mechanisms of this issue as follows "theorists often conveniently put authors against translators; sometimes as rivals, sometimes as a servant, but less likely in an equation, i.e., in a relationship between the translators and readers (Cary, 1963). As such, to overcome the obsolete dichotomy of the author versus translators, Edmund uses a third word called the reader. He refers to one of the best French translators of Renaissance, Amyot, who takes into account the author as much as he accounts for the translator" (Guidère, 2011).

In Germany, Friedrich Schleiermacher was the first to theorize translation issue from a similar perspective. In his view, there are two real translation methods: taking the author towards the reader or guiding the reader to the author. This binary concept was expanded in Germany and gained a particular position in the tradition of German linguistics.

\subsection{Original versus Copy}

The concepts of "original" and "copy", though often taken for granted, are entirely relative as they depend on the context and the period in question. It was only in the twentieth century that a precise definition of these two terms was proposed. In the contemporary era, the perception of this concept is associated with the audience and the country under question. Glances at a large number of countries in which copyrights are violated suffice to endorse this point. According to Ballard, between the seventh and twelfth centuries, the very act of retelling a story from any language in English was considered as original (Ballard, 1992). During the Middle Ages, original writings were often seen as the source of inspiration and the act of writing was hardly distinguished from the act of translations as both actions (writing and reading) were undertaken by the same person.

Until modern times, the concept of "original" was too vague. There are many cases wherein a text is written based on a translation or a translation of another translation is produced.

\subsection{Fidelity versus Betrayal}

One of the oldest theories of translatology is concerned with the issue of fidelity in translation, which can be divided into two categories: loyalty and betrayal. Some questions have been raised in this regard, e.g., "should a translator remain faithful to the ST or TT?" "Is fidelity attributed to the text or the language?" "Should the translator remain true to the source author or the target reader?" "Should a translator stay loyal to the culture of the SL or TL culture?"

\subsection{Domestic versus Foreign}

The nineteenth century is simultaneous with the rise of nationalism across Europe. Under this condition, dichotomies like domestic versus foreign were formed. In response to this trend, most countries posed different reactions, depending on their position in the international community. By the late eighteenth century, most French authors had a tendency to write pedantically. The general tendency was to adapt to the taste of French audience in search of a kind of beauty through style. The French taste was even involved in the selection of themes and authors. It can be said that in the age of Romanticism, the translation was treated as a political subject. Meschonnic says, "When national literature took shape, no distinction was made between translation and writing until they found that translation was, in fact, a recounting of the words of others. Then, the concept of world literature was proposed" (Guidère, 2011).

There is a host of dichotomies in translation studies including the literary vs. scientific-technical, human vs. computer-aided translation, written vs. conference interpreting and so forth.

\section{Discussion}

The translatology of Ladmiral is philosophical in nature, but Meschonnic is more geared towards literary theory. Translation studies are struggling to find its place among other disciplines that strive to incorporate it into their body of theories. Thus, the translation is assumed to be a branch of comparative linguistics, applied linguistics, text linguistics, the psychology of language and intercultural relationship. In the same vein, literary, philosophical and anthropological approaches should not be overlooked. Translation has been explored from a variety of perspectives, but none has fully covered the scope of its studies. As such, translatology is still interdisciplinary in nature. It borrows its concepts and methods from other disciplines. Traditionally, translation studies have been classified in the realm of humanities as a branch of linguistics, though still part of it can be traced to the natural sciences and neuroscience. Some translation studies work through data modeling. "Was automatic translation not the origin of the automatic processing of languages in 1950?" "Is Computer Assisted Translation software an indication of the scientific nature of translatology?" According to Guidère, there is an internal translatology that specifically deals with the translation phenomenon and an external translatology (Traductologie extern) that considers translation as a product of political, historical, sociological and other issues. But in any case, there is a translatology that is receptive of human sciences impact sand achievements (Guidère, 
2011).

\section{Conclusions}

Such as most sciences, translation studies have concepts and paradigms of its own, some of which were discussed in this paper. As an interdisciplinary field, translation studies seek to establish its position in the humanities as an independent discipline, though this is not to say that it cannot benefit from the achievement of other disciplines.

In one classification, Ladmiral divides translation into four discourses, which embody four theoretical methods of addressing translatology. Although in Ladmiral's view prescriptive discourse has no position, translation textbooks are still reminiscent of the popularity of this discourse. We believe that the fourth discourse (scientific translatology) is not of immediate help to a translator, and its necessity is not felt. The two other discourses, especially the productive translatology, play a pivotal role, which is helpful to a translator. As soon as the issue of fidelity in translation is raised, the translation of scriptures is invoked to the mind. In short, the literal translation is the preferred method for rendering scriptures but for literary texts, a sense for sense rendering is favored.

The source oriented and target oriented, two coinages introduced in the French language by Ladmiral, have the advantage of illustration. As for binary concepts, it should be noted that they constitute the building block of translatology from an epistemological perspective. Translation studies are strongly related tothe translatability and untranslatability, or fidelity in translation.

\section{References}

Cary, E. (1963). Les Grand's traducers français. Genève: Georg.

Guidère, M. (2011). Introduction à la traductology: Spenser la traduction her, aujourd'hui, domain. Bruxelles.

Ladmiral, J. R. (1971). Le Discoursscientifique. Revue d'esthétique, t. XXVI, n 2-3, 153-191.

Ladmiral, J. R. (1986). Sourciers et ciblistes. Revue d'esthétique, n 12, 33-42.

Ladmiral, J. R. (1987). Traductologiques. In M.-J. Capelle, F. Debyser, \& J.-L. Goester (Eds.), Retour à la traduction: numérospécial de la revue Le françaisdans le monde (pp. 18-25).

Ladmiral, J. R. (1998). Approches en théorie de la traduction. Traduction: approches et theories (pp. 12-37). Beyrouth.

Ladmiral, J. R. (2002). Traduire: théorèmes pour la traduction. Paris: Gallimard.

Mounin, G. (1955). Les belles infidels. Paris: Cahier du Sud.

Mounin, G. (1976). Linguistique et traduction. Bruxelles: Pessert et Mordaga.

Oustinoff, M. (2003). La traduction, Paris, PUF. Quesais-je, n 3688.

Van Hoof, H. (1991). Histoire de la traduction en Occident: France, Grande-Bretagne, Allemagne, Russie, Pays-Bas. Paris: Duculot.

Vinay, J. P., \& Darbelnet, J. (1958). Stylistiquecomparée du français et de l'anglais. Paris: Didier.

Zendehboudi, M. (2007). La traductologiefrançaise (pp. 23-79). Machhad: Mohaqeq.

\section{Copyrights}

Copyright for this article is retained by the author(s), with first publication rights granted to the journal.

This is an open-access article distributed under the terms and conditions of the Creative Commons Attribution license (http://creativecommons.org/licenses/by/4.0/). 